\title{
Occupational Commitment of Chinese Kindergarten Teachers During the COVID-19 Pandemic: Predictions of Anti-Epidemic Action, Income Reduction, and Career Confidence
}

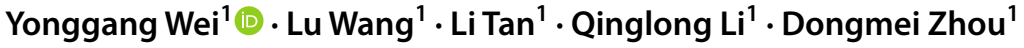

Accepted: 20 June 2021 / Published online: 5 July 2021

(c) The Author(s), under exclusive licence to Springer Nature B.V. 2021

\begin{abstract}
This study highlights a survey on 5783 kindergarten teachers' occupational commitment and its influencing factors in the socioeconomic context of China during the COVID-19 pandemic. Data were collected through the WenJuanXing public online platform. Quantitative analysis results showed that kindergarten teachers' occupational commitment was optimistic on the whole during this period, among which the affective commitment and the normative commitment were satisfactory, but the continuing commitment needed to be strengthened. The type of kindergartens, the personnel affiliation, the educational background, and the professional post of kindergarten teachers had significant impacts on their occupational commitment. The income reduction was negatively correlated with and predictive of kindergarten teachers' occupational commitment. Anti-epidemic action and career confidence were positively correlated with and predictive of kindergarten teachers' occupational commitment. Furthermore, anti-epidemic action, income reduction, and career confidence had joint predictive effects on kindergarten teachers' occupational commitment. More related backgrounds and suggestions have been discussed.
\end{abstract}

Keywords COVID-19 Occupational commitment $\cdot$ Kindergarten teachers

\section{Introduction}

Since the global outbreak of the COVID-19 pandemic, governments all over the world have carried out a series of prevention and control measures, including close restraints on going out and public gatherings, temporarily closing public places, the implementation of strict body temperature detection, calling for people to wear a face mask, shutting down enterprises and factories, closing schools, quarantine at home, and more (Kuntz, 2021; Liu et al., 2020). These emergency response measures have indeed effectively reduced the transmission of the COVID-19 pandemic and slowed the growth rate of cases (Tian et al., 2020). Meanwhile, the COVID-19 pandemic has a non-negligible impact on the social and economic fields and the normal operation

Yonggang Wei

cqws001@cqnu.edu.cn

1 Chongqing Early Childhood Education Quality Monitoring and Evaluation Research Center, Chongqing Normal University, No. 37 Middle Road, University Town, Gaoxin District, Chongqing 401331, China of industries (Wang et al., 2021). The stress response and career survival of organizations and their members, such as the education system and teachers, under the impact of the COVID-19 pandemic are of special concerns.

\section{Education Under the Impact of the COVID-19 Pandemic}

In response to the COVID-19 pandemic, a large number of schools are closed, and children and adolescents who were supposed to be in school have to be isolated at home. Since March 2020, approximately 1.5 billion students worldwide have been affected by pandemic control needs (Lancet, 2021). According to the Global Education Monitoring Report released by the UNESCO (2020), at least 500 million children and adolescents have been excluded from public education, despite the efforts by governments around the world to provide alternative online learning during the pandemic. More than $60 \%$ of countries adopting distance learning have relied entirely on online platforms, but close to 465 million children and adolescents in 
these countries have had difficulty accessing the internet at home (Giannini, 2020), which has led to inequality in access to educational opportunities. In addition, different from school-aged children and teenagers, the education for preschoolers depends on various activities that let them participate personally. To achieve meaningful learning results, preschoolers need to gain experience through effective interaction with the environment, teachers, and other children in the activities. This learning characteristic of preschoolers is difficult to satisfy by distance education on the internet. The COVID-19 pandemic makes preschoolers have to stay at home, unable to go out to play or engage in peer interaction. At this point, the home educational environment becomes extremely important for the development of children and adolescents. However, at this time, the pandemic continues to impact the incomes and savings of the majority of families, and more and more families may fall into poverty, which further aggravates the possibility that children and adolescents may face a poor family environment, and in turn may have serious consequences for their lifelong development (Luo et al., 2020).

In addition to the impact on the students and educational implementation patterns, the COVID-19 pandemic also has an ongoing influence on the career ecosystem of teachers. As educators, teachers are the necessary human capital for the healthy development of education. Nevertheless, during the pandemic period, teachers could not return to school to carry out normal teaching and research work. Whereas, due to the national and local government policies and the requirements of education institutions, teachers have been asked to continue their educational activities in an unusual way during the COVID-19 pandemic. In addition, the sudden outbreak of the pandemic significantly increased the cognitive and emotional burden of teachers. Besides dealing with common pressures in daily work, they also need to balance their work and family life during the pandemic period, improve their technical literacy required for the online work, and take care of the health and safety of their students (Sokal et al., 2021). As the COVID-19 pandemic progresses, teachers may become more tired, and tend to be more negative in terms of cognitive and emotional attitudes toward their work and career. In addition, the shortage of teaching and research resources caused by the pandemic will further aggravate the pressure and burnout of teachers (Sokal et al., 2020a, 2020b). Teachers have experienced strong emotional shocks in the COVID-19 pandemic, such as the constant fear of being infected with the virus or losing their job, along with various concerns related to their professional duties as a teacher (Dayal \& Tiko, 2020).

\section{Career Ecosystem of Kindergarten Teachers Under the COVID-19 Pandemic}

Since the outbreak of the pandemic, the early childhood education industry has been greatly affected. Kindergartens were unable to open and resume services for a long time. A large number of kindergartens face a shortage of operating funds, and have failed to adapt to this changing education situation; experiencing the failure of the management of the education timetable plan, and accordingly, being unable to maintain a good education status, especially in terms of adjusting the timetable (Putra et al., 2020). Governments have introduced relevant prevention and control policies to maintain public health, and the mandatory closure of childcare services has a direct impact on labor demand. For example, the promulgation of the stay-at-home orders has led to a significant decline in the number of preschool teacher positions, and the labor market seems to have rebounded after the abolition of those bills (Ali et al., 2021). A study from Indonesia showed that during the COVID-19 pandemic, kindergartens accepted their governments' management plans and regulations, and applied for distance education with related facilities; however, many kindergarten management committees encountered difficulties in completing the planned educational timetable and goals (Munastiwi \& Puryono, 2021). The stressors of traumatic events such as the COVID-19 pandemic have exposed the problems of the existing education system and the lack of supports for early childhood educators (Eadie et al., 2021). Under this public health emergency, teachers have had to face challenging working conditions, which assume new roles and responsibilities, and demand new working methods (Beames et al., 2021). Work difficulties and challenges may become important sources of professional pressure for kindergarten teachers (Bergdahl \& Nouri, 2020). Alan (2021) found that preschool teachers lacked of the teaching strategies or experience required for distance education, and that they also needed to improve their technological competencies, increase practices that serve and support families, and ensure psychological well-being.

For China's education system, kindergarten teachers are the educators for 3 to 6-year-old children, who are a group worthy of special attention compared to the other grade levels. They face a relatively special professional ecological environment. Chinese kindergarten teachers are usually divided into public servant kindergarten teachers (PSKTs) and temporary service contract kindergarten teachers (TSCKTs). Almost having lifetime employment, PSKTs are the same as state civil servants, whose salaries are paid by government. TSCKTs are employed by kindergartens (both private and public ones included), who seems more like temporary contract workers, without guarantee of lifetime 
employment. For the TSCKTs, although there is a national policy pointing out that their salaries and benefits should be equal to those of the PSKTs, their wages are mainly affected by the market supply and paid by their employers, not by the government. Therefore, facing the COVID-19 pandemic, PSKTs and TSCKTs may have different attitudes toward their work and career, which could possibly result in the loss and more severe insufficiency of kindergarten teachers. The income of PSKTs is not greatly affected by the COVID-19 pandemic due to the government financial support. On the contrary, the income of TSCKTs who originally had a lower income is reduced to varying degrees, and some of them cannot get any income during the COVID-19 pandemic. In order to make a living, a lot of TSCKTs have had to give up the career of being a kindergarten teacher and turn to other industries that recovered earlier during the COVID19 pandemic (Hong et al., 2021), which further enlarges the existing gap of the demand for kindergarten teachers. Since private kindergartens are currently the main force of early childhood education and care in China, and there are still a large number of TSCKTs in public kindergartens, a large loss of the TSCKTs will not only cause a severe inadequacy of kindergarten teachers, but also may cause more anxiety and pressure on the PSKTs.

A stable and high-quality contingent of kindergarten teachers is the premise and strong guarantee for the development of early childhood education and care. It has been demonstrated that occupational commitment can effectively predict the stability of the employee team and their situation of job performance (Yin et al., 2018). Therefore, it is necessary for us to focus on the occupational commitment of kindergarten teachers during the COVID-19 pandemic, explore the influencing factors on their occupational commitment in the special situation of the pandemic, and then, put forward pertinent suggestions to improve their occupational commitment in order to cope with unexpected public health emergencies, so as to prevent kindergarten teachers from being employed and leaving when unexpected public health emergencies happen.

\section{Factors Affecting Teachers' Occupational Commitment}

Relevant studies have shown that individual traits and external environments are important factors affecting occupational commitment (De Jong, 1999; London, 1983). Among them, environmental factors related to work have a stronger effect on one's occupational commitment, such as teachers' participation in decision-making and management, information feedback to teachers, cooperation between teachers, learning opportunities for teachers, and resources available to teachers (Firestone \& Pennell, 1993). Individual factors affecting one's occupational commitment mainly include some demographic variables, such as gender, age, position, education level, and so on. The research on the relations among individual education level, position, and occupational commitment has demonstrated that the higher the education level and the position are, the higher the level of occupational commitment is, possibly because the stability and pleasure of the related career lead to higher occupational commitment (Goulet \& Singh, 2002).

The research of Nägele \& Neuenschwander (2014) indicates that occupational commitment depends on positive social integration and can be predicted by social integration, task mastery, the adjustment process, and pre-employment adaptation for young workers. In addition, there is a positive correlation between job characteristics and occupational commitment (Jiang et al., 2020). Longer working time in a career is associated with higher scores for occupational commitment (Gwyn, 2011; Meyer et al., 1993). Occupational commitment is also related to professional working attitudes (Riegle-Crumb et al., 2020). The research on how perceptions of vocational competence and interactions with others in the field predict STEM teachers' occupational commitment has shown that positive teacher interactions do significantly predict occupational commitment. According to Sun (2018), due to the differences in gender, working years, marital status, and educational background, there are also significant differences in occupational commitment among individuals, and job burnout is negatively correlated with occupational commitment. Occupational commitment is negatively correlated with turnover intention and job performance (Cooper-Hakim \& Viswesvaran, 2005). Career satisfaction and job challenge also affect affective commitment (Meyer et al., 1993).

Teachers' occupational commitment is directly proportional to their self-efficacy. According to $\mathrm{Ng}$ and Lucianetti (2015), self-efficacy refers to the ways in which individuals hold beliefs about their ability to make things happen through their own actions. Teachers' beliefs in teaching can predict their occupational commitment (Chan et al., 2008; Ware \& Kitsantas, 2007). There is a strong inverse relation between pressure and teachers' occupational commitment. High levels of teaching pressure can lead to low morale, reduced work efficiency, increased absenteeism, and reduced occupational commitment (Hakanen et al., 2006; Jepson \& Forrest, 2006). Overburdened by a public health emergency, teachers are trying to balance teaching responsibilities with stressful life situations exacerbated by the outbreak of the COVID-19 pandemic, including the sudden need for teaching children online at home and caring for their own family members, colleagues, and even themselves (MacIntyre et al., 2020). During the COVID-19 pandemic, teachers' selfefficacy has been relatively low, due to higher job requirements and fewer teaching resources, and difficulty adapting to online teaching, which brings unsatisfactory pressure 
teaching self-efficacy, work stress, and teaching environment affect the experienced teachers' and pre-service teachers' occupational commitment and turnover intentions. Self-efficacy can mediate the influence of teachers' pressure on their occupational commitment. Self-efficacy of teaching strategies affects the occupational commitment of experienced teachers, and self-efficacy related to classroom management affects the pre-service teachers' occupational commitment.

During the COVID-19 pandemic, schools around the world have had to choose to make changes in the ways of teaching and learning, such as distance learning, while many teachers' income has become significantly lower than that before the pandemic. Teachers' engagement, income reduction, and policy impact can affect their intention to leave the field (Hoang et al., 2020). As researchers have pointed out, by ignoring teachers' welfare, we will have more incidental problems (Doucet et al., 2020).

\section{Aims of the Current Study}

This study adopts the three-dimension theory proposed by Meyer and Allen (1991), dividing occupational commitment into affective commitment, normative commitment, and continuing commitment. The affective commitment refers to individuals' strong willingness to continue to engage in a certain career. The normative commitment refers to the sense of responsibility and obligation of individuals to engage in a certain career. The continuing commitment refers to individuals' cognition of the cost of leaving and giving up a certain career, and the degree of willingness to engage in the current career for a long time.

We focus on the situation and influencing factors of the occupational commitment of kindergarten teachers in China during the COVID-19 pandemic. London (1983) believed that both individual traits and external environments were important factors affecting occupational commitment, and De Jong (1999) found that work factor was also an important variable affecting occupational commitment. Therefore, we consider the influencing factors of kindergarten teachers' occupational commitment from individual and environment aspects, among which the environmental factors related to work have a stronger influence on kindergarten teachers' occupational commitment.

There are two environmental factors which have been typically related to kindergarten teachers' occupational commitment during the special COVID-19 period, respectively called income reduction and anti-epidemic action. For the anti-epidemic action, the early childhood education and care community has been widely involved in China's antiepidemic campaign, and some non-governmental organizations and associations have also launched online activities to offer advice and contributions to developing Chinese early childhood education and care. Kindergarten teachers' anti-epidemic action refers to their concerns and participation in a series of anti-epidemic activities, which can improve their occupational commitment. In terms of income reduction, as mentioned above, many kindergartens suffer from the shortage of funds due to the COVID-19 pandemic, and the income of a considerable number of kindergarten teachers has been reduced to some degree; this is especially true for the TSCKTs. This type of income reduction can trigger the turnover and loss of kindergarten teachers.

Besides the above two environmental factors, there is also an individual factor which is typically related to Chinese kindergarten teachers' occupational commitment during the COVID-19 pandemic: career confidence. This refers to kindergarten teachers' confidence about the future development of early childhood education and care, which is associated with economic growth and social employment situation under the strike of the pandemic. As we know, under the impact of the pandemic, economic development and employment are worrisome. The delay in returning to work could reduce the expectations and confidence of kindergarten teachers for their future career. Thus, the confidence $n$ economic development, employment, and the future development of early childhood education and care may affect kindergarten teachers' occupational commitment.

Hereby, the hypotheses of this study are as follows. (1) The anti-epidemic action has a positive impact on kindergarten teachers' occupational commitment; and the higher the teachers' involvement, the higher their occupational commitment will be. (2) The income reduction has a negative impact on the occupational commitment of kindergarten teachers; and the higher the percentage of income reduction, the lower their occupational commitment will be. (3) Career confidence has a positive impact on the occupational commitment of kindergarten teachers, and the higher the career confidence, the higher their occupational commitment will be.

\section{Method}

\section{Participants}

The data for this study were sampled by administering an anonymous electronic questionnaire on the WenJuanXing public online platform (https://www.wjx.cn) to kindergarten teachers in China during a spreading period of the COVID-19 pandemic, from March 16 to March 27 in 2020. Chongqing Early Childhood Education Quality Monitoring and Evaluation Research Center of Chongqing Normal University provided ethical approval to conduct the study. Kindergarten teachers were free to decide whether to fill out the questionnaire or not after reading the guidance for the questionnaire, which stated the purpose and the 
privacy policy of this study. The data were screened by checking the filling time of the questionnaire, and those with filling time less than 5 min were regarded as being invalid and rejected. Eventually, 5783 valid data were retained, which were filled out by kindergarten teachers from 32 provincial administrative units in China. The detailed sample information is shown in Table 1.

\section{Measures}

\section{Occupational Commitment Measure}

This study took the Kindergarten Teachers' Occupational Commitment Questionnaire developed by Kang (2008) to measure kindergarten teachers' occupational commitment, which is in line with the three-dimension theory proposed by Meyer and Allen (1991). The questionnaire has altogether fourteen items, including affective commitment (four items), normative commitment (six items), and continuing commitment (four items). All items are Likert-type rating scales, scored from 1 (completely disagree) to 5 (completely agree); the higher the score shows, the higher kindergarten teachers' occupational commitment is. In this study, the Cronbach's alpha coefficient of the scale is 0.88 , and the confirmatory factor analysis fitting indexes are as follows: $\chi^{2} / d f=32.84\left(\chi^{2}=2430.35, d f=74\right), G F I=0.94$, $C F I=0.95, I F I=0.95, T L I=0.94, R M S E A=0.07$. Except that $\chi^{2} / d f$ is slightly larger due to the influence of the large sample, all the other fitting indexes are satisfactory.

\section{Anti-Epidemic Action Measure}

The anti-epidemic action refers to kindergarten teachers' concerns and participation in a series of anti-epidemic activities, such as understanding of early childhood education and care policies for combating the COVID-19 pandemic, giving attention to social public platforms related to combating the COVID-19 pandemic, communicating with peers on combating the COVID-19 pandemic, and efforts to improve early childhood education and care. The scale for the anti-epidemic action contains four items, all of which are Likert-type rating scale, scored from 1 (strongly disagree) to 5 (strongly agree). The higher the score indicates the greater the kindergarten teachers' level of anti-epidemic action involvement. In this study, the Cronbach's alpha coefficient of the scale is 0.74 .

\section{Income Reduction Measure}

In current study, the income reduction measure is not a scale method. The income reduction of kindergarten teachers during the COVID-19 pandemic was measured by the ratio of their income to that during the non-pandemic period. There was only one question for the participants: "My income during the pandemic is of that during the non-pandemic period." The options from high to low were 100\%, 99-75\%, $74-50 \%, 49-25 \%$, and 24-0\% respectively. The scores of 0 to 4 have been assigned to the data encoding correspondingly; the higher the score shows, the greater the income reduction is.
Table 1 Sample information $(N=5783)$

\begin{tabular}{lllr}
\hline Variables & Levels & $n$ & $\%$ \\
\hline Gender & Male & 79 & 1.36 \\
& Female & 5704 & 98.64 \\
Professional post & Senior & 332 & 5.74 \\
& Intermediate & 1185 & 20.49 \\
& Junior & 1428 & 24.69 \\
Educational degree & None & 2838 & 49.08 \\
& Junior college degree and below & 2920 & 50.49 \\
Type of kindergarten & Bachelor degree and above & 2863 & 49.51 \\
& Public & 4205 & 72.71 \\
Personnel affiliation & Private & 1578 & 27.29 \\
& Public servant kindergarten teacher (PSKT) & 2774 & 47.97 \\
& Temporary service contract kindergarten teacher & 3009 & 52.03 \\
Major & (TSCKT) & & \\
& Early childhood education and care & 4585 & 79.28 \\
& Not early childhood education and care & 1198 & 20.72 \\
\hline
\end{tabular}




\section{Career Confidence Measure}

Career confidence refers to kindergarten teachers' confidence in the development prospects of early childhood education and care, economic growth, and social employment situation during the pandemic. The scale for the career confidence contained three items, all of which are Likert-type rating scale, scored from 1 (strongly disagree) to 5 (strongly agree). The higher the score shown, the higher the kindergarten teachers' career confidence is. In this study, the Cronbach's alpha coefficient of the scale is 0.78 .

\section{Common Method Deviation Avoidance}

The survey data of this study were adopted by the participants' self-report, which may have a common methods bias effect. To reduce this kind of effect, the questionnaire was administrated in the way of an anonymous network investigation, the instructions for the participants indicated that the results of the study were used only for academic research, and the confidentiality was emphasized. The participants volunarily took part in the investigation. Exploratory factor analysis was conducted in this study to test the possible common method bias effect. The results showed that there were 5 factors (affective commitment, normative commitment, continuing commitment, anti-epidemic action, and career confidence) with the eigenvalues greater than 1 , and the explanation rate of the first common factor was $33.35 \%$, which was less than the critical standard of $40 \%$, indicating that there was no serious common method bias effect in this study. The
Cronbach's alpha coefficient of the whole scale was 0.80 , including the measures on the occupational commitment, the anti-epidemic action, and the career confidence.

\section{Results}

\section{Descriptive Statistics and Correlation Analysis of Each Variable}

The descriptive statistical results (see Table 2) show that the score of occupational commitment is 3.75 , higher than the critical value 3 , indicating that the overall level of occupational commitment of kindergarten teachers is optimistic during the COVID-19 pandemic. The scores of the normative commitment and the affective commitment of kindergarten teachers are higher than the value of 4 , among which the score of normative commitment is the highest. However, the score on continuing commitment is 2.93 , lower than the critical value 3 , and indicating that there is still a certain gap between the continuing commitment of kindergarten teachers and the satisfactory level of occupational commitment during the COVID-19 pandemic. The score of the anti-epidemic action is 3.96, and the score of the career confidence is 3.29 , both higher than the critical value 3 , indicating that the anti-epidemic action and the career confidence of kindergarten teachers are all right during the COVID-19 pandemic. Pessimistically, the score of income reduction is 1.48 , indicating that the income of kindergarten teachers has been generally

Table 2 Score of each variable

\begin{tabular}{llllllll}
\hline & $\begin{array}{l}\text { Occupational } \\
\text { commitment }\end{array}$ & $\begin{array}{l}\text { Affective } \\
\text { commitment }\end{array}$ & $\begin{array}{l}\text { Normative } \\
\text { commitment }\end{array}$ & $\begin{array}{l}\text { Continuing } \\
\text { commitment }\end{array}$ & $\begin{array}{l}\text { Anti- } \\
\text { epidemic } \\
\text { action }\end{array}$ & $\begin{array}{l}\text { Income } \\
\text { reduction }\end{array}$ & $\begin{array}{l}\text { Career } \\
\text { confi- } \\
\text { dence }\end{array}$ \\
\hline $\mathrm{M}$ & 3.75 & 4.02 & 4.29 & 2.93 & 3.96 & 1.48 & 3.29 \\
$\mathrm{SD}$ & 0.53 & 0.71 & 0.55 & 0.82 & 0.56 & 1.70 & 0.93 \\
\hline
\end{tabular}

Table 3 Correlations between each variable

$\begin{array}{llllll}\begin{array}{l}\text { Occupational } \\ \text { commitment }\end{array} & \begin{array}{l}\text { Affective } \\ \text { commitment }\end{array} & \begin{array}{l}\text { Normative } \\ \text { commitment }\end{array} & \begin{array}{l}\text { Continuing } \\ \text { commitment }\end{array} & \begin{array}{l}\text { Anti-epi- } \\ \text { demic action }\end{array} & \begin{array}{l}\text { Income reduction } \\ \text { confi- } \\ \text { dence }\end{array}\end{array}$

\begin{tabular}{llllllll}
\hline Occupational commitment & 1 & & & & & \\
Affective commitment & $0.82^{* *}$ & 1 & & & & \\
Normative commitment & $0.77^{* *}$ & $0.70^{* *}$ & 1 & & & \\
Continuing commitment & $0.70^{* *}$ & $0.25^{* *}$ & $0.20^{* *}$ & 1 & $0.09^{* *}$ & 1 & \\
Anti-epidemic action & $0.40^{* *}$ & $0.44^{* *}$ & $0.44^{* *}$ & $-0.15^{* *}$ & 1 \\
Income reduction & $-0.20^{* *}$ & $-0.09^{* *}$ & $-0.16^{* *}$ & $-0.20^{* *}$ & $-0.26^{* *}$ & 1 \\
Career confidence & $0.25^{* *}$ & $0.28^{* *}$ & $0.26^{* *}$ & $0.08^{* *}$ & $0.20^{* *}$ & - \\
\hline
\end{tabular}

${ }^{* *} P<0.01$ 
reduced between $25 \%$ and $50 \%$ in average during the COVID-19 pandemic.

Pearson correlation analysis results (see Table 3 ) show that there are significantly negative correlations between the income reduction and the occupational commitment and its sub-dimensions (the affective commitment, the normative commitment, and the continuing commitment), the anti-epidemic action, and the career confidence. Except for these negative relations, the correlations between all the other variables are significantly positive.

\section{Occupational Commitment Differences on Demographic Variables}

Independent sample t-test results and One-way variance results (see Table 4) show that the type of kindergartens (public or private), the personnel affiliation (PSKTs or TSCKTs), the educational background (majoring in early childhood education or without majoring in early childhood education, junior college degree and below or bachelor degree and above), and the professional post (senior, intermediate, junior, or none) have significant impacts on the occupational commitment of kindergarten teachers during the COVID-19 pandemic, but the role of gender is not significant in the special period.

In terms of the occupational commitment and its subdimensions, teachers in public kindergartens are significantly higher than those in private kindergartens. Except for the affective commitment, the scores of the occupational commitment and the other two sub-dimensions of the PSKTs are significantly higher than those of the TSCKTs. In terms of the occupational commitment and its sub-dimensions, the scores of the kindergarten teachers whose major is not early childhood education before entry are significantly higher than those of the early childhood education majoring teachers. As to the affective commitment, the score of the kindergarten teachers with junior college degree and below is significantly higher than that of the teachers with bachelor degree and above. In terms of continuing commitment, the kindergarten teachers with a bachelor's degree and above are significantly higher than those with a junior college degree and below. There are no significant differences between the kindergarten teachers with a junior college degree and below

Table 4 Independent sample t-test and one-way variance analysis

\begin{tabular}{|c|c|c|c|c|c|c|c|c|c|}
\hline \multirow[t]{2}{*}{ Variables } & & \multicolumn{2}{|c|}{$\begin{array}{l}\text { Occupational com- } \\
\text { mitment }\end{array}$} & \multicolumn{2}{|c|}{$\begin{array}{l}\text { Affective com- } \\
\text { mitment }\end{array}$} & \multicolumn{2}{|c|}{$\begin{array}{l}\text { Normative com- } \\
\text { mitment }\end{array}$} & \multicolumn{2}{|c|}{$\begin{array}{l}\text { Continuing com- } \\
\text { mitment }\end{array}$} \\
\hline & & M & SD & M & SD & M & SD & M & SD \\
\hline \multirow[t]{3}{*}{ Gender } & Male & 3.72 & 0.74 & 3.89 & 0.96 & 4.22 & 0.77 & 3.04 & 0.88 \\
\hline & Female & 3.75 & 0.53 & 4.02 & 0.71 & 4.29 & 0.55 & 2.93 & 0.82 \\
\hline & $T$ & -0.40 & & -1.28 & & -0.85 & & 1.21 & \\
\hline \multirow[t]{3}{*}{ Educational degree } & Junior college degree and below & 3.75 & 0.51 & 4.08 & 0.65 & 4.28 & 0.54 & 2.89 & 0.83 \\
\hline & Bachelor degree and above & 3.75 & 0.54 & 3.97 & 0.77 & 4.31 & 0.56 & 2.97 & 0.82 \\
\hline & $T$ & 0.02 & & $5.80^{* * *}$ & & -1.90 & & $-3.73^{* * *}$ & \\
\hline \multirow[t]{3}{*}{ Type of kindergarten } & Public & 3.80 & 0.51 & 4.07 & 0.71 & 4.35 & 0.54 & 2.99 & 0.82 \\
\hline & Private & 3.61 & 0.54 & 3.9 & 0.71 & 4.15 & 0.56 & 2.77 & 0.81 \\
\hline & $T$ & $12.66^{* * *}$ & & $7.78^{* * *}$ & & $12.1^{* * * *}$ & & $9.26^{* * *}$ & \\
\hline \multirow[t]{3}{*}{ Personnel affiliation } & PSKT & 3.83 & 0.51 & 4.03 & 0.72 & 4.34 & 0.53 & 3.12 & 0.8 \\
\hline & TSCKT & 3.67 & 0.53 & 4.02 & 0.71 & 4.24 & 0.56 & 2.76 & 0.81 \\
\hline & $T$ & $11.61^{* * * *}$ & & 0.82 & & $7.02^{* * *}$ & & $17.12^{* * * *}$ & \\
\hline \multirow[t]{3}{*}{ Major } & Early childhood education and care & 3.74 & 0.53 & 4.01 & 0.72 & 4.28 & 0.55 & 2.92 & 0.82 \\
\hline & Not early childhood education and care & 3.8 & 0.52 & 4.07 & 0.69 & 4.33 & 0.55 & 3 & 0.83 \\
\hline & $T$ & $-3.68^{* * * *}$ & & $-2.33^{*}$ & & $-2.85^{* *}$ & & $-3.17^{* *}$ & \\
\hline \multirow[t]{8}{*}{ Professional post } & 1 Senior & 3.92 & 0.47 & 4.13 & 0.66 & 4.39 & 0.52 & 3.24 & 0.8 \\
\hline & 2 Intermediate & 3.85 & 0.51 & 4.05 & 0.68 & 4.35 & 0.52 & 3.16 & 0.79 \\
\hline & 3 Junior & 3.74 & 0.53 & 3.97 & 0.74 & 4.28 & 0.55 & 2.98 & 0.81 \\
\hline & 4 None & 3.69 & 0.53 & 4.03 & 0.72 & 4.26 & 0.56 & 2.78 & 0.81 \\
\hline & $F$ & $39.97^{* * *}$ & & $5.84^{* * *}$ & & $11.53^{* * *}$ & & $83.00^{* * * *}$ & \\
\hline & $L S D$ & $1>2 \& 3 \& 4$ & & $1>3 \& 4$ & & $1 \& 2>3 \& 4$ & & $1 \& 2>3 \& 4$ & \\
\hline & & $2>3 \& 4$ & & $2 \& 4>3$ & & & & $3>4$ & \\
\hline & & $3>4$ & & & & & & & \\
\hline
\end{tabular}

${ }^{*} P<0.05,{ }^{* *} P<0.01,{ }^{* * *} P<0.001$ 
and those with a bachelor's degree and above in terms of occupational commitment and normative commitment. The scores of occupational commitment and its three sub-dimensions of the kindergarten teachers with different professional posts are significantly different. Taking a specific view with the LSD post-test, we find that the higher the kindergarten teachers' professional title is, the higher the score of the occupational commitment is. In terms of the affective commitment, the normative commitment, and the continuing commitment, the LSD post-test results are in line with such a tendency in general except that the scores between the kindergarten teachers with senior title and those with intermediate title are not significantly different, and that the score of the kindergarten teachers without any title is higher than that of the kindergarten teachers with junior title in the term of the affective commitment.

\section{Predictions of Anti-Epidemic Action, Income Reduction, and Career Confidence to Occupational Commitment}

Considering kindergarten teachers' occupational commitment and its three sub-dimensions as dependent variables, and the anti-epidemic action, the income reduction, and the career confidence as independent variables, the stepwise regression analysis has been taken to explore the predictive effects (see Table 5).

It is evident from Table 5 that the anti-epidemic action takes a significant and positive role in solely or jointly predicting kindergarten teachers' occupational commitment and its sub-dimensions except the continuing commitment. Income reduction takes a significant but negative role in jointly predicting kindergarten teachers' occupational commitment and its sub-dimensions except the affective commitment, and it can dominantly predict the continuing commitment. Career confidence takes a significant and positive role in jointly predicting kindergarten teachers' occupational commitment and its sub-dimensions except the continuing commitment.

\section{Discussion}

\section{Characteristics of Kindergarten Teachers' Occupational Commitment during the COVID-19 Pandemic}

The occupational commitment of kindergarten teachers is a key indicator to measure whether kindergarten teachers will be engaged in and committed to the profession of early childhood education and care for a long time, and it will have an important impact on their professional behaviors and endeavors to providing early childhood education services (Morrison, 1994). Occupational commitment affects employees not only on their career-related attitudes, such as occupational turnover intention (Chang et al., 2007), but also on their job performances. Empirical studies have shown that employees with higher occupational commitment

Table 5 Stepwise regression analysis

\begin{tabular}{|c|c|c|c|c|c|c|c|c|}
\hline Dependent variables & Model & Independent variables & $B$ & $\beta$ & $t$ & $R^{2}$ & Adjusted $R^{2}$ & $F$ \\
\hline \multirow[t]{6}{*}{ Occupational commitment } & 1 & Anti-epidemic action & 0.37 & 0.40 & $32.85^{* * *}$ & 0.16 & 0.16 & $1078.82^{* * * *}$ \\
\hline & \multirow[t]{2}{*}{2} & Anti-epidemic action & 0.34 & 0.36 & $29.74^{* * *}$ & \multirow[t]{2}{*}{0.19} & \multirow[t]{2}{*}{0.19} & \multirow[t]{2}{*}{$669.85^{* * *}$} \\
\hline & & Career confidence & 0.10 & 0.18 & $14.83^{* * *}$ & & & \\
\hline & \multirow[t]{3}{*}{3} & Anti-epidemic action & 0.33 & 0.35 & $28.90^{* * * *}$ & \multirow[t]{3}{*}{0.20} & \multirow[t]{3}{*}{0.20} & \multirow[t]{3}{*}{$481.52^{* * *}$} \\
\hline & & Career confidence & 0.09 & 0.15 & $12.31^{* * *}$ & & & \\
\hline & & Income reduction & -0.04 & -0.11 & $-9.24^{* * *}$ & & & \\
\hline \multirow[t]{3}{*}{ Affective commitment } & 1 & Anti-epidemic action & 0.56 & 0.44 & $37.13^{* * *}$ & 0.19 & 0.19 & $1378.84^{* * *}$ \\
\hline & \multirow[t]{2}{*}{2} & Anti-epidemic action & 0.51 & 0.40 & $33.81^{* * *}$ & \multirow[t]{2}{*}{0.23} & \multirow[t]{2}{*}{0.23} & \multirow[t]{2}{*}{$863.59^{* * *}$} \\
\hline & & Career confidence & 0.15 & 0.20 & $16.78^{* * * *}$ & & & \\
\hline \multirow[t]{6}{*}{ Normative commitment } & 1 & Anti-epidemic action & 0.43 & 0.44 & $37.38^{* * *}$ & 0.20 & 0.19 & $1397.11^{* * *}$ \\
\hline & \multirow[t]{2}{*}{2} & Anti-epidemic action & 0.40 & 0.41 & $34.30^{* * *}$ & \multirow[t]{2}{*}{0.22} & \multirow[t]{2}{*}{0.22} & \multirow[t]{2}{*}{$829.79^{* * *}$} \\
\hline & & Career confidence & 0.10 & 0.17 & $14.55^{* * *}$ & & & \\
\hline & \multirow[t]{3}{*}{3} & Anti-epidemic action & 0.39 & 0.40 & $33.68^{* * * *}$ & \multirow[t]{3}{*}{0.23} & \multirow[t]{3}{*}{0.23} & \multirow[t]{3}{*}{$565.11^{* * * *}$} \\
\hline & & Career confidence & 0.09 & 0.16 & $12.90^{* * *}$ & & & \\
\hline & & Income reduction & -0.02 & -0.06 & $-5.29^{* * *}$ & & & \\
\hline \multirow[t]{3}{*}{ Continuing commitment } & 1 & Income reduction & -0.10 & -0.20 & $-15.65^{* * *}$ & 0.04 & 0.04 & $245.02^{* * * *}$ \\
\hline & \multirow[t]{2}{*}{2} & Income reduction & -0.09 & -0.19 & $-14.83^{* * *}$ & \multirow[t]{2}{*}{0.04} & \multirow[t]{2}{*}{0.04} & \multirow[t]{2}{*}{$133.65^{* * *}$} \\
\hline & & Anti-epidemic action & 0.09 & 0.06 & $4.63^{* * * *}$ & & & \\
\hline
\end{tabular}

${ }^{* * *} P<0.001$ 
exhibit better job performance (Lee et al., 2000) and lower organizational turnover intention (Chang et al., 2007; Jepson $\&$ Forrest, 2006). Studies on teachers have shown that a high level of occupational commitment can effectively reduce their turnover intention, promote the stability of the teacher team, reduce teacher loss, and improve job performance (Xie et al., 2011). It is found in this study that the occupational commitment and its sub-dimensions of Chinese kindergarten teachers during the COVID-19 pandemic is generally above the medium level except the continuing commitment, and in order from high to low, the sub-dimensions of the occupational commitment are the normative commitment, the affective commitment, and the continuing commitment. This finding indicates that the COVID-19 pandemic itself does not bring negative effects on kindergarten teachers' occupational commitment and its sub-dimensions, except the continuing commitment.

This finding can be accounted for by the job characteristic model proposed by Hackman and Oldham (1976), which describes the methods that organizations can use to activate employees' positive responses to work, such as intrinsic motivation, meaning, and responsibility, to perform better. Employees who find their core job characteristics inspiring will also have positive feelings about their career (Jiang et al., 2020). As we know, the career of early childhood education and care is full of vitality, and young children are naive and lively, so kindergarten teachers are easily impacted by their interactions with young children. Besides, most kindergartens have been in charge of classes for three years, and have deep feelings towards the children in their classes, so they remain positive and optimistic in their work and have a strong desire to teach. This explanation is consistent with the finding given by Ware and Kitsantas (2007), which demonstrates that occupational commitment is in direct proportion to teaching willingness. According to Wang (2013), the overall level of occupational happiness of kindergarten teachers in China is relatively high. In the view of the extended construction theory of positive emotions (Fredrickson, 2001), the occupational happiness of kindergarten teachers may have a strong predictive power on their occupational commitment. There is a significant relation between teachers' career satisfaction and occupational commitment (Sakalli Demirok, 2017), and teachers' satisfaction with their career has an impact on their firmer commitment to their career. Each dimension of kindergarten teachers' occupational happiness is positively correlated with the affective commitment, the normative commitment, and the continuing commitment to different degrees (Wang, 2013). Job satisfaction, which means teachers' emotional feelings about the profession they are engaged in, affects occupational commitment. The higher the job satisfaction, the higher the affective commitment and the normative commitment is (Jiang et al., 2020; Meyer et al., 2002).
As to continuing commitment, studies have shown that this is less related to job satisfaction, and mainly related to career pressure (Klassen et al., 2013; Meyer et al., 2002). Teachers' stress is inversely proportional to occupational commitment and is associated with a strong desire to leave their profession (Jepson \& Forrest, 2006; Klassen \& Chiu, 2011). During the COVID-19 pandemic, the difficulty and challenges of work are the main source of professional pressure for kindergarten teachers. In the process of online teaching, teachers face a series of challenges, such as the use of technology being a difficult problem and the lack of teaching strategies needed in the distance learning environment (Lindahl \& Folkesson, 2012). A high level of teaching pressure may reduce teachers' occupational commitment or make them abandon the profession soon after entering the career (Conley \& You, 2009). For teachers, the high level of work pressure can lead to low enthusiasm, low work efficiency and reduced occupational commitment (Hakanen et al., 2006). Especially, the reduction of continuing commitment can make some teachers be absent from work, and even decide to quit their profession (Jepson \& Forrest, 2006). In conclusion, because of lower professional status and salary but heavier workload than other educational grade levels, many kindergarten teachers lack the positive intention for a long-term career. Furthermore, suffering pressure from online teaching, home care, and income reduction due to the COVID-19 outbreak, kindergarten teachers' aspirations to continue in their teaching careers are even weaker (Cheng et al., 2020).

\section{Differences of Occupational Commitment between Public and Private Kindergarten Teachers}

This study has found that there are significant differences in occupational commitment and its sub-dimensions of the teachers under different types of kindergartens. The scores of occupational commitment and its sub-dimensions of the teachers in public kindergartens are significantly higher than those of the teachers in private kindergartens. Since most kindergarten teachers are female in China, they are more inclined to choose a stable and secure job according to Chinese gender role culture (Kang, 2007), and public kindergartens have this advantage even during the COVID19 pandemic. Working hours are an important indicator of job requirements (Wu et al., 2010), and the teachers in public kindergartens have more time and holidays to spend by themselves, so their subjective well-being is relatively high (Dagenais-Desmarais \& Savoie, 2012; Sonnentag, 2012). Therefore, the occupational commitment of the teachers in public kindergartens is significantly higher than that of the teachers in private kindergartens. Because the funds of private kindergarten are backed by personal preparations or other social forces, all the expenditures including teachers' 
professional development training shall be borne by the private kindergarten itself. Due to a number of factors, such as training costs and limited financial resources, there exist common problems such as low wages, large workload, work pressure, and welfare and social insurance not fully safeguard in private kindergartens (You, 2019). Under the COVID-19 pandemic, due to the school closure policy, the uncertainty of kindergarten suspension and resumption increased (Wang et al., 2020), which resulted in the vast majority of private kindergartens having no source of income and not being able to meet the teachers' desire to pursue a stable life; the basic salary of kindergarten teachers cannot be guaranteed. On the contrary, public kindergartens have more career resources and financial supports for teachers, which can meet some basic needs of them, such as stable income, professional title, welfare, and ability developing (Ryan \& Deci, 2000). Career development is a process of self-validation of one's work. This positive self-validation enhances the sense of self-worth that often triggers positive reactions and emotional attachment to one's current career. Reward advances such as salary increases and promotion to senior titles allow people to experience more autonomy in terms of their financial situation and the use of work resources (Jiang et al., 2020). Hall and Chandler (2005) also proposed that an individual's response to his current job was not only influenced by the characteristics of the job itself, but also by its broad career prospects. This contrast between the private and public kindergartens has become even more pronounced due to the COVID-19 outbreak, which further shakes the belief inf continuing the work in private kindergartens, and then lowers the level of private kindergarten teachers' occupational commitment. Therefore, the occupational commitment and its sub-dimensions of the teachers in private kindergartens is significantly lower than that of the teachers in public kindergartens.

\section{Differences of Occupational Commitment Between PSKTs and TSCKTs}

According to the results in this study, there are significant differences in occupational commitment between the PSKTs and the TSCKTs. The occupational commitment and its subdimensions of PSKTs are significantly higher than those of TSCKTs. Public servant system can give teachers a certain life safeguard, bring teachers a certain benefits, enhance teachers' sense of security (Wang, 2018). The subjective well-being of the PSKTs is significantly higher than that of the TSCKTs (Wei, 2014), which may explain the serious problems of kindergarten teachers in China who are resigning. Moreover, the PSKTs mostly obtain their positions through their own unremitting efforts, and they know the hardships involved in getting such a job, so they cherish their posts more. However, the job threshold of the TSCKTs is relatively low, and they do not cherish their posts as the PSKTs (Feng, 2020). The salary of the TSCKTs is usually much lower than that of the PSKTs, and the practice of different pay for the same work is very common in public kindergartens between the two groups, which is unfair for the TSCKTs (Wei, 2014). Under the impact of the COVID-19 pandemic, the income reduction percentage of the TSCKTs is much more serious than that of the PSKTs $(\mathrm{MD}=1.84$, $p<0.001$ ), and some private kindergarten programs have even had to lay off teachers in order to save costs and maintain the daily operation of the program, which may have impacted the occupational commitment and its sub-dimensions for the TSCKTs.

\section{Positive Predictive Effects of Anti-Epidemic Action to Kindergarten Teachers' Occupational Commitment}

The results of this study show that the anti-epidemic action had a significant and positive predictive effect on the occupational commitment and its sub-dimensions of kindergarten teachers. This finding has verified the hypothesis of our stud;, that is, kindergarten teachers' occupational commitment will be affected by the variable, anti-epidemic action. The survey data show that only $3.30 \%$ of the kindergarten teachers did not pay attention to the national and local early childhood education and care policies related to the COVID19 pandemic, $2.18 \%$ of the kindergarten teachers did not pay attention to the anti-epidemic activities carried out by the community of early childhood education and care, and $5.34 \%$ of the kindergarten teachers did not focus on the antiepidemic information pushed by China National Society of Early Childhood Education. It can be seen that during the COVID-19 outbreak, the kindergarten teachers themselves have paid more attention to and participated in the antiepidemic activities concerning the development of early childhood education and care. Meanwhile, Central People's Government of the People's Republic of China issued the Notice on Scientific and Accurate Prevention and Control of COVID-19 pandemic in Accordance with the Law, which provided the COVID-19 control technology scheme for childcare organizations and institutions. Under the leadership and policy of national and local governments, a series of anti-epidemic activities have provided social supports for kindergarten teachers, which strengthens their confidence in the fight against the pandemic for the development of early childhood education and care, and thus has a positive impact on their occupational commitment.

Lian and Shao (2003) have pointed out that school culture is directly related to teachers' occupational commitment, and school leadership behavior can affect teachers' work motivation and the culture of the whole school. Effective leaders can strike a balance between existing resources 
and teachers' job demands, thus reducing job burnout, and affecting teachers' job satisfaction and occupational commitment (Sokal et al., 2021). In order to build a high quality teaching force, most kindergarten leaders attach importance to the continuing education of kindergarten teachers. During the COVID-19 pandemic period, they continued to carry out teaching and research activities online with various resources, provided teachers timely guidance and educational training, and strengthened their interpersonal communication and collaborations with colleagues and leaders. Therefore, it provides a good management condition for the improvement of kindergarten teachers' occupational commitment. London (1983) believed that both individual traits and external environment could affect occupational commitment, and the combined effect of external conditions and internal feelings was more likely to positively improve the level of occupational commitment of kindergarten teachers. The theme of the 2020 Early Childhood Education Publicity Month hosted by Ministry of Education of PRC and China National Society of Early Childhood Education is "Different Accompanying in Special Time", which records and shows the wonderful moments when kindergarten teachers accompany children and parents to grow together during the COVID-19 pandemic. Positive comments and attitudes from the public make kindergarten teachers feel support and respect from the society, which enhances the feelings of kindergarten teachers for the work in early childhood education and care, thus improving their psychological adaptation to the occupation, and improving the level of occupational commitment.

\section{Negative Predictive Effects of Income Reduction to Kindergarten Teachers' Occupational Commitment}

This study has found that during the COVID-19 pandemic, the income reduction of kindergarten teachers had a negative predictive effect on their occupational commitment and its sub-dimensions. This result is consistent with previous studies. For example, the study of Normala (2010) demonstrated that salary and benefits were positively correlated with employees' occupational commitment. Kang (2007) found that there was a significant correlation between salary and the level of occupational commitment of kindergarten teachers. Salary is an important factor that affects whether teachers continue to work or not (Shang \& Shen, 2017), which may lead to employee turnover (Buchanan et al., 2013). Worthington (2008) pointed out that public health emergencies not only caused direct damage to the affected areas, but also affected the functioning of the supply chain, allowing the risk to be transferred to the unaffected areas, thus causing a large number of direct and indirect economic losses. The sudden outbreak of the COVID-19 pandemic has affected all walks of life to varying degrees. While kindergarten programs delayed opening, their costs of staff wages, rent, property management fees, daily operation expenditure were still continuously spending. Different from the public kindergartens, as discussed above, the survival pressure of the private kindergartens in China is more serious, and the majority of them have had to reduce the wages for their teachers. According to Stinebrickner (1998), wage reductions can most effectively trigger teachers to leave their positions; meanwhile, a higher income can help teachers to treat their work and life with calm and positive attitudes, and thus a virtuous circle forms. Affected by the COVID-19 pandemic, the income of kindergarten teachers was cut down significantly, especially the income of teachers in the private kindergartens decreased more significantly $($ mean $=3.19$, $\max =4$, at the reduction level of $80 \%$ ). This reduction may decrease kindergarten teachers' motivation and enthusiasm, which in turn can shake their resolve to stay in their current jobs.

\section{Positive Predictive Effects of Career Confidence to Kindergarten Teachers' Occupational Commitment}

The occupational commitment of teachers is the link between teachers and their profession, among which the affective commitment, the normative commitment, and the continuing commitment respectively reflect the different ties in feelings, ethics, and economy. This study has found that career confidence has a significant and positive predictive effect on kindergarten teachers' occupational commitment. Specifically, career confidence significantly positively predicts the affective commitment and the normative commitment of kindergarten teachers, but does not directly predict their continuing commitment. This may be accounted for by the social supports from organizations and policies. Chen (2016) found that teachers' occupational commitment was affected by organizational environment, and the supports from friends, families, and organizations had a greater impact on their occupational commitment. Furthermore, the impacts on affective commitment and normative commitment were greater, while the impact on continuing commitment was lighter. This COVID-19 pandemic is another sudden public crisis since SARS, which has had great negative impacts on countries all over the world. In spite of this, personalized and "Internet +" industries such as online video and audio, online games, online education, online office, e-commerce and e-logistics have ushered in a golden opportunity for development (Wang, 2020). These industry trends may enhance kindergarten teachers' career confidence on Chinese social and economic development, including the healthy development of early childhood education and care. In addition, in response to the call for "Suspension 
of classes, but no suspension of learning" and "Suspension of classes, but no suspension of teaching" proposed by Ministry of Education of P.R.C., all the schools and kindergartens across the country have started online education activities, which also inspires kindergarten teachers' confidence on the career in early childhood education and care, and strengthens their normative commitment. On the other hand, faced with a new online working environment and relatively flexible office time, kindergarten teachers are able to control the pace of work by themselves, which may enable them to obtain higher occupational commitment, especially in terms of affective commitment. According to a previous study, the occupational commitment of teachers could be predicted through a harmonious, free, and relaxed professional environment (Bogler \& Nir, 2015). Another study found that development opportunities for kindergarten teachers provided an external source of motivation for the improvement of their occupational commitment (Chen $\& \mathrm{He}, 2015)$. When kindergarten teachers realize that they have the opportunity to self-realize, they are willing to invest more emotionally in their careers, and they are more likely to pursue their career aspirations. Generally speaking, the more supports kindergarten teachers get from their organizations, the higher their occupational commitment level will be. The reason why career confidence cannot directly predict the continuing commitment of kindergarten teachers may be related to teachers' career satisfaction. According to Meyer et al. (1993), the higher the degree of challenge an individual engages in, the lower the level of his/her occupational commitment is; the higher the degree of career satisfaction an individual experiences, the higher the level of his/her occupational commitment is. After the policy of "Suspension of classes, but no suspension of learning" and "Suspension of classes, but no suspension of teaching", the emergence of various online education resources has brought many new technical and teaching challenges to kindergarten teachers (Gao et al., 2020), which increases the burden of kindergarten teachers and the career pressure accordingly, while strengthening their career confidence. Despite those antiepidemic efforts and career confidence, we cannot deny the fact that the professional environment of kindergarten teachers is still not optimistic, their career pressure is still high, and their income is still unsatisfactory. On the one hand, they are emotionally attached to the field of early childhood education and care and hold the confidence that everything will get better; on the other hand, they have to face the reality that their professional environment has been changed and that there are many challenges for their work and life. This may also account for the joint predictive effects of the anti-epidemic action, the income reduction, and the career confidence to kindergarten teachers' occupational commitment and its sub-dimensions.

\section{Conclusion}

This study investigated Chinese kindergarten teachers' occupational commitment in the socioeconomic context of China during the outbreak of the COVID-19 pandemic. It has been found that the occupational commitment of kindergarten teachers is optimistic on the whole even under the impact of the COVID-19 pandemic, among which the affective commitment and the normative commitment are satisfactory, but the continuing commitment needs to be strengthened. The occupational commitment level of the teachers in public kindergartens is significantly higher than that of the teachers in private ones. The occupational commitment level of PSKTs is significantly higher than that of TSCKTs. The income reduction among kindergarten teachers is a common emergency phenomenon during the COVID-19 pandemic, and especially serious among the TSCKTs. The income reduction is significantly negatively correlated with and predictive to the occupational commitment of kindergarten teachers during this special period. The anti-epidemic action and the career confidence are significantly positively correlated with and predictive to the occupational commitment of kindergarten teachers during the COVID-19 pandemic. Furthermore, the anti-epidemic action, the income reduction, and the career confidence have joint predictive effects on kindergarten teachers during the COVID-19 pandemic.

\section{Strengths and Limitation}

This study reflected the general picture of kindergarten teachers' occupational commitment with a large size sample covering 32 provincial administrative units in China under the socioeconomic context of the COVID-19 pandemic. The predictive effects of the three variables, anti-epidemic action, income reduction, and career confidence, were analyzed not only respectively but also jointly, which enlarged our perspectives on the mechanism of kindergarten teachers' occupational commitment and the strategy for improving their occupational commitment while encountering this public health emergency.

Our findings confirm the impact of the public health emergency on the occupational commitment of kindergarten teachers, especially the impact on the continuing commitment of kindergarten teachers. According to these findings, in the post-pandemic era and during unexpected coming public health emergencies, in order to strengthen kindergarten teachers' occupational commitment and avoid their turnover intentions, state and local governments should increase the financial input to early childhood education and care, and make appropriate policies to help kindergartens overcome difficulties, such as setting up anti-risk funds for 
them, improving the salary level of kindergarten teachers, and considering the salary of TSCKTs into the financial guarantee. In addition, an effective salary mechanism should be established, such as setting up risk insurance funds for kindergarten teachers, reducing the gap in the wages and benefits between the PSKTs and the TSCKTs.

This article is a cross-sectional study during the special period of the COVID-19 pandemic, in which it is difficult to reveal the lasting impact of the COVID-19 pandemic on the occupational commitment of kindergarten teachers. For researchers in those areas where the COVID-19 pandemic is still going on, it is worthy to carry on longitudinal follow-up studies to explore its continuous or intermittent impact on the occupational commitment of kindergarten teachers during different pandemic phases. Additionally, our work only investigated the effects of the three factors, including antiepidemic action, income reduction, and career confidence, on the occupational commitment of kindergarten teachers. For the interaction of some other related factors, which may also affect the occupational commitment of kindergarten teachers, we have not explored yet. It is necessary to carry on further studies to investigate more factors affecting the occupational commitment of kindergarten teachers during the outbreak or normalization of the pandemic, with crosscultural and multinational cooperation and comparison, to reveal more profound mechanisms of and more productive strategies for kindergarten teachers' occupational commitment while suffering from pandemics.

Acknowledgements This study is funded by the Chongqing Social Science Planning Project (No. 2019YBJJ102) and the Chongqing University Outstanding Talents Support Program.

\section{Declarations}

Conflict of interest We declare no potential conflicts of interest with respect to the research, authorship, and/or publication of this article.

\section{References}

Alan, Ü. (2021). Distance education during the COVID-19 pandemic in Turkey: Identifying the needs of early childhood educators. Early Childhood Education Journal. https://doi.org/10.1007/S10643021-01197-Y (prepublish).

Ali, U., Herbst, C. M., \& Makridis, C. A. (2021). The impact of COVID-19 on the US child care market: Evidence from stay-athome orders. Economics of Education Review, 82(1), 102094. https://doi.org/10.1016/j.econedurev.2021.102094

Beames, J. R., Christensen, H., \& Werner-Seidler, A. (2021). School teachers: The forgotten frontline workers of COVID-19. Australasian Psychiatry. https://doi.org/10.1177/10398562211006145

Bergdahl, N., \& Nouri, J. (2020). COVID-19 and crisis-prompted distance education in Sweden. Technology Knowledge and Learning. https://doi.org/10.1007/s10758-020-09470-6
Bogler, R., \& Nir, A. E. (2015). The contribution of perceived fit between job demands and abilities to teachers' commitment and job satisfaction. Educational Management Administration \& Leadership, 43(4), 541-560. https://doi.org/10.1177/17411 43214535736

Buchanan, J., Prescott, A., Schuck, S., Aubusson, P., Burke, P., \& Louviere, J. (2013). Teacher retention and attrition: Views of early career teachers. Australian Journal of Teacher Education, 38(3), 112-129. https://doi.org/10.14221/ajte.2013v38n3.9

Chan, W. Y., Lau, S., Nie, Y., Lim, S., \& Hogan, D. (2008). Organizational and personal predictors of teacher commitment: The mediating role of teacher efficacy and identification with school. American Educational Research Journal, 45(3), 597-630. https://doi.org/10.3102/0002831208318259

Chang, H. T., Chi, N. W., \& Miao, M. C. (2007). Testing the relationship between three-component organizational/occupational commitment and organizational/occupational turnover intention using a non-recursive model. Journal of Vocational Behavior, 70(2), 352-368. https://doi.org/10.1016/j.jvb.2006.10.001

Chen, S. P., \& He, Z. F. (2015). Research on the status quo and influencing factors of preschool teachers' professional commitment in Jiangxi province. Journal of Vocational Education, 32, 14-19. (in Chinese).

Chen, X. M. (2016). Correlation study on professional commitment and social support of teachers in special education school. China Journal of Health Psychology, 10, 1451-1454. (in Chinese).

Cheng, L., Zhang, H. M., Wu, X. P., \& Chen, H. (2020). The impact of psychological capital on occupational commitment of preschool teachers: A moderated mediation model. Teacher Education Research, 32(04), 87-95. (in Chinese).

Conley, S., \& You, S. (2009). Teacher role stress, satisfaction, commitment, and intentions to leave: A structural model. Psychological Reports, 105(3), 771-786. https://doi.org/10.2466/PR0. 105.3.771-786

Cooper-Hakim, A., \& Viswesvaran, C. (2005). The construct of work commitment: Testing an integrative framework. Psychological Bulletin, 131(2), 241-259. https://doi.org/10.1037/0033-2909. 131.2.241

Dagenais-Desmarais, V., \& Savoie, A. (2012). What is psychological well-being, really? A grassroots approach from the organizational sciences. Journal of Happiness Studies, 13(4), 659-684. https://doi.org/10.1007/s10902-011-9285-3

Dayal, H. C., \& Tiko, L. (2020). When are we going to have the real school? A case study of early childhood education and care teachers' experiences surrounding education during the COVID-19 pandemic. Australasian Journal of Early Childhood, 45(4), 336-347. https://doi.org/10.1177/1836939120966085

De Jong, E. (1999). The impact of motivation on the career commitment of Dutch literary translators. Poetics, 26(5-6), 423-437. https://doi.org/10.1016/s0304-422x(99)00010-8

Doucet, A., Netolicky, D., Timmers, K., \& Tuscano, F. J. (2020). Thinking about pedagogy in an unfolding pandemic: An independent report on approaches to distance learning during COVID19 school closures. https://teachertaskforce.org/knowl edge-hub/thinking-about-pedagogy-unfolding-pandemic.

Eadie, P., Levickis, P., Murray, L., Elek, C., \& Church, A. (2021). Early childhood educators' wellbeing during the COVID-19 pandemic. Early Childhood Education Journal. https://doi.org/ 10.1007/s10643-021-01203-3

Feng, M. J. (2020). Research on the current situation and influential factors of professional commitment of newly qualified kindergarten teachers. Unpublished master thesis. Shenyang Normal University. (in Chinese)

Firestone, W. A., \& Pennell, J. R. (1993). Teacher commitment, working conditions, and differential incentive policies. Review 
of Educational Research, 63(4), 489-525. https://doi.org/10. 3102/00346543063004489

Fredrickson, B. L. (2001). The role of positive emotions in positive psychology: The broaden-and-build theory of positive emotions. American Psychologist, 56(3), 218-226. https://doi.org/ 10.1037/0003-066x.56.3.218

Gao, X. Y., Qin, Y. Y., \& Lv, K. R. (2020). Problems faced by online learning and challenges to teachers' teaching. Modern Vocational Education, 49, 10-11. (in Chinese).

Giannini, S. (2020). Distance learning denied. World Education Blog. https://gemreportunesco.wordpress.com/2020/05/15/distancelearning-denied/.

Goulet, L. R., \& Singh, P. (2002). Career commitment: A reexamination and an extension. Journal of Vocational Behavior, 61(1), 73-91. https://doi.org/10.1006/jvbe.2001.1844

Gwyn, P. G. (2011). The quality of mentoring relationships' impact on the occupational commitment of nursing faculty. Journal of Professional Nursing, 27(5), 292-298. https://doi.org/10.1016/j. profnurs.2011.03.008

Hackman, J. R., \& Oldham, G. R. (1976). Motivation through the design of work: Test of a theory. Organizational Behavior and Human Performance, 16(2), 250-279. https://doi.org/10.1016/ 0030-5073(76)90016-7

Hakanen, J. J., Bakker, A. B., \& Schaufeli, W. B. (2006). Burnout and work engagement among teachers. Journal of School Psychology, 43(6), 495-513. https://doi.org/10.1016/j.jsp.2005.11.001

Hall, D. T., \& Chandler, D. E. (2005). Psychological success: When the career is a calling. Journal of Organizational Behavior, 26(2), 155-176. https://doi.org/10.1002/job.301

Hoang, A. D., Ta, N. T., Nguyen, Y. C., Hoang, C. K., Nguyen, T. T., Pham, H. H., Nguyen, L. C., Doan, P. T., Dao, Q. A., \& Dinh, V. H. (2020). Dataset of ex-pat teachers in southeast Asia's intention to leave due to the COVID-19 pandemic. Data in Brief, 31, 105913. https://doi.org/10.1016/j.dib.2020.105913

Hong, X. M., Zhao, S., \& Zhang, M. (2021). How to solve the predicament of the loss of kindergarten teachers. Modern Education Management, 01, 69-75. (in Chinese).

Jepson, E., \& Forrest, S. (2006). Individual contributory factors in teacher stress: The role of achievement striving and occupational commitment. British Journal of Educational Psychology, 76(1), 183-197. https://doi.org/10.1348/000709905X37299

Jiang, Y., Wang, Q., \& Weng, Q. (2020). Job characteristics as drivers of occupational commitment: The mediating mechanisms. Current Psychology. https://doi.org/10.1007/s12144-020-00755-8

Kang, X. X. (2007). The study of developmental characteristics and influential factors of kindergarten teachers' professional commitment. Unpublished master thesis. East China Normal University, Shanghai. (in Chinese)

Kang, X. X. (2008). Development characteristics of kindergarten teachers' occupational commitment. Studies in Preschool Education, 09, 39-42. (in Chinese).

Klassen, R. M., \& Chiu, M. M. (2011). The occupational commitment and intention to quit of practicing and pre-service teachers: Influence of self-efficacy, job stress, and teaching context. Contemporary Educational Psychology, 36(2), 114-129. https://doi.org/10. 1016/j.cedpsych.2011.01.002

Klassen, R., Wilson, E., Siu, A. F. Y., Hannok, W., Wong, M. W., Wongsri, N., Sonthisap, P., Pibulchol, C., Buranachaitavee, Y., \& Jansem, A. (2013). Preservice teachers' work stress, self-efficacy, and occupational commitment in four countries. European Journal of Psychology of Education, 28(4), 1289-1309. https://doi. org/10.1007/s10212-012-0166-x

Kuntz, J. C. (2021). Resilience in times of global pandemic: Steering recovery and thriving trajectories. Applied Psychology: An International Review, 70(1), 188-215. https://doi.org/10.1111/ apps.12296
Lee, K., Carswell, J. J., \& Allen, N. J. (2000). A meta-analytic review of occupational commitment: Relations with person- and workrelated variables. Journal of Applied Psychology, 85(5), 799-811. https://doi.org/10.1037/0021-9010.85.5.799

Lian, R., \& Shao, Y. L. (2003). Research on teachers' professional commitment and its development model. Education Review, 06, 26-28. (in Chinese).

Lindahl, M. G., \& Folkesson, A. M. (2012). ICT in preschool: Friend or foe? the significance of norms in a changing practice. International Journal of Early Years Education, 20(4), 422-436. https://doi.org/10.1080/09669760.2012.743876

Liu, Q., Xu, K., Wang, X., \& Wang, W. (2020). From SARS to COVID-19: What lessons have we learned? Journal of Infection and Public Health, 13(11), 1611-1618. https://doi.org/10. 1016/j.jiph.2020.08.001

London, M. (1983). Toward a theory of career motivation. Academy of Management Review, 8(4), 620-630. https://doi.org/10.5465/ AMR.1983.4284664

Luo, R., Liu, C., Gao, J., Wang, T., Zhi, H., Shi, P., \& Huang, J. (2020). Impacts of the COVID-19 pandemic on rural poverty and policy responses in China. Journal of Integrative Agriculture, 19(12), 2946-2964. https://doi.org/10.1016/S20953119(20)63426-8

MacIntyre, P. D., Gregersen, T., \& Mercer, S. (2020). Language teachers' coping strategies during the COVID-19 conversion to online teaching: Correlations with stress, wellbeing and negative emotions. System, 94, 102352. https://doi.org/10.1016/j.system.2020. 102352

Meyer, J. P., \& Allen, N. J. (1991). A three-component conceptualization of organizational commitment. Human Resource Management Review, 1(1), 61-89. https://doi.org/10.1016/1053-4822(91) 90011-Z

Meyer, J. P., Allen, N. J., \& Smith, C. A. (1993). Commitment to organizations and occupations: Extension and test of a three-component conceptualization. Journal of Applied Psychology, 78(4), 538551. https://doi.org/10.1037/0021-9010.78.4.538

Meyer, J. P., Stanley, D. J., Herscovitch, L., \& Topolnytsky, L. (2002). Affective, continuance, and normative commitment to the organization: A meta-analysis of antecedents, correlates, and consequences. Journal of Vocational Behavior, 61(1), 20-52. https:// doi.org/10.1006/jvbe.2001.1842

Morrison, E. W. (1994). Role definitions and organizational citizenship behavior: The importance of the employee's perspective. The Academy of Management Journal, 37(6), 1543-1567. https://doi. org/10.2307/256798

Munastiwi, E., \& Puryono, S. (2021). Unprepared management decreases education performance in kindergartens during COVID19 pandemic. Heliyon, 7(5), e07138. https://doi.org/10.1016/j. heliyon.2021.e07138

Nägele, C., \& Neuenschwander, M. P. (2014). Adjustment processes and fit perceptions as predictors of organizational commitment and occupational commitment of young workers. Journal of Vocational Behavior, 85(3), 385-393. https://doi.org/10.1016/j. jvb.2014.08.011

Ng, T., \& Lucianetti, L. (2015). Within-individual increases in innovative behavior and creative, persuasion, and change self-efficacy over time: A social-cognitive theory perspective. The Journal of Applied Psychology. https://doi.org/10.1037/ap10000029

Normala, D. (2010). Investigating the relationship between quality of work life and organizational commitment amongst employees in Malaysian firms. International Journal of Business and Management, 5(10), 75-82. https://doi.org/10.5539/ijbm.v5n10p20

Putra, P., Liriwati, F. Y., Tahrim, T., Syafrudin, S., \& Aslan, A. (2020). The students learning from home experiences during COVID19 school closures policy in Indonesia. Jurnal Iqra, 5(2), 30-42. https://doi.org/10.25217/ji.v5i2.1019 
Riegle-Crumb, C., Peng, M., \& Russo-Tait, T. (2020). Committed to STEM? examining factors that predict occupational commitment among Asian and white female students completing stem U.S. postsecondary programs. Sex Roles, $82,102-116$. https://doi.org/ 10.1007/s11199-019-01038-8

Ryan, R. M., \& Deci, E. L. (2000). Self-determination theory and the facilitation of intrinsic motivation, social development, and wellbeing. American Psychologist, 55(1), 68-78. https://doi.org/10. 1037/0003-066X.55.1.68

Sakalli Demirok, M. (2017). Career satisfaction and professional commitment of special education teachers. Quality \& Quantity, 52, 1187-1199. https://doi.org/10.1007/s11135-017-0667-4

Shang, W. W., \& Shen, G. T. (2017). Research on the relationship of preschool teachers' occupational commitment and turnover intention: The mediation effect of the quality of work life. Education Research Monthly, 07, 74-82. (in Chinese).

Sokal, L. J., Trudel, L. G. E., \& Babb, J. C. (2020). Supporting teachers in times of change: The job demands-resources model and teacher burnout during the COVID-19 pandemic. International Journal of Contemporary Education, 3(2), 67-74. https://doi.org/10.11114/ ijce.v3i2.4931

Sokal, L. J., Trudel, L. G. E., \& Babb, J. C. (2021). I've had it! factors associated with burnout and low organizational commitment in Canadian teachers during the second wave of the COVID-19 pandemic. International Journal of Educational Research Open, 2-2, 100023. https://doi.org/10.1016/j.ijedro.2020.100023

Sokal, L., Trudel, L. E., \& Babb, J. (2020b). Canadian teachers' attitudes toward change, efficacy, and burnout during the COVID-19 pandemic. International Journal of Educational Research Open, 1, 100016. https://doi.org/10.1016/j.ijedro.2020.100016

Sonnentag, S. (2012). Psychological detachment from work during leisure time: The benefits of mentally disengaging from work. Current Directions in Psychological Science, 21(2), 114-118. https://doi.org/10.1177/0963721411434979

Stinebrickner, T. R. (1998). An empirical investigation of teacher attrition. Economics of Education Review, 17(2), 127-136. https://doi. org/10.1016/S0272-7757(97)00023-X

Sun, X. (2018). Interdependent interaction of occupational burnout and organizational commitments: case study of academic institutions located in Guangxi province, China. Studies in systems, decision and controlIn M. Amini, K. Boroojeni, S. Iyengar, P. Pardalos, F. Blaabjerg, \& A. Madni (Eds.), Sustainable interdependent networks. Springer.

Lancet, T. (2021). COVID-19: The intersection of education and health. The Lancet, 397(10271), 253. https://doi.org/10.1016/ S0140-6736(21)00142-2

Tian, H., Liu, Y., Li, Y., Wu, C. H., Chen, B., Kraemer, M. U. G., Li, B., Cai, J., Xu, B., Yang, Q., Wang, B., Yang, P., Cui, Y., Song, Y., Zheng, P., Wang, Q., Bjornstad, O. N., Yang, R., Grenfell, B. T., ... Dye, C. (2020). An investigation of transmission control measures during the first 50 days of the COVID-19 epidemic in China. Science, 368(6491), 638-642. https://doi.org/10.1126/ science.abb6105

UNESCO. (2020). Education: From disruption to recovery. https://en. unesco.org/covid19/educationresponse.
Wang, B., Liu, Y., Qian, J., \& Parker, K. S. (2021). Achieving effective remote working during the COVID-19 pandemic: A work design perspective. Applied Psychology: An International Review, 70(1), 16-59. https://doi.org/10.1111/apps. 12290

Wang, G. F. (2013). The characteristics of kindergarten teachers' occupational well-being and its relationship with occupational commitment. Psychological Development and Education, 29(06), 616-624. (in Chinese).

Wang, G. F. (2018). An analysis of the present situation of the professional commitment of rural private kindergarten teachers and countermeasures. Journal of Heilongjiang Institute of Teacher Development, 37(01), 40-43. (in Chinese).

Wang, G. H., Zhang, Y. T., Zhao, J., Zhang, J., \& Jiang, F. (2020). Mitigate the effects of home confinement on children during the COVID-19 outbreak. The Lancet, 395(10228), 945-947. https:// doi.org/10.1016/S0140-6736(20)30547-X

Wang, S. Y. (2020). On the prospect of world economy under the impact of pneumonia epidemic in COVID-19. Reform \& Opening, 15, 61-65. (in Chinese).

Ware, H., \& Kitsantas, A. (2007). Teacher and collective efficacy beliefs as predictors of professional commitment. The Journal of Educational Research, 100(5), 303-310. https://doi.org/10.2307/ 27548194

Wei, Y. G. (2014). The influence of personnel affiliation of preschool teachers on subjective well-being. Education Review, 03, 51-53. (in Chinese).

Worthington, A. C. (2008). The impact of natural events and disasters on the Australian stock market: A GARCH-M analysis of storms, floods, cyclones, earthquakes and bushfires. Global Business and Economics Review, 10(1), 1. https://doi.org/10.1504/gber.2008. 016824

Wu, L., Zhang, D., \& Wu, X. C. (2010). The effect of job characteristics on workers: Comparison between DC model and JD-R model. Advances in Psychological Science, 18(02), 348-355. (in Chinese).

Xie, L. L., Gong, Y. Z., \& Zhang, Q. (2011). Occupational psychological investigation about the loss of rural teachers: Based on the relationship among teachers' self-esteem, occupational commitment and organizational citizenship behavior. China Rural Survey, 01, 60-72. (in Chinese).

Yin, H., Wang, W., Huang, S., \& Li, H. (2018). Psychological capital, emotional labor and exhaustion: Examining mediating and moderating models. Current Psychology, 37(1), 343-356. https://doi. org/10.1007/s12144-016-9518-Z

You, X. Y. (2019). Research on the professional commitment of teachers in private kindergartens in Chongqing. Unpublished master thesis. Southwest University, Chongqing. (in Chinese)

Publisher's Note Springer Nature remains neutral with regard to jurisdictional claims in published maps and institutional affiliations. 